\title{
Isolation and Characterization of Staphylococci from External Auditory Meatus of Dogs with or without Otitis Externa with Special Reference to Staphylococcus schleiferi subsp. coagulans Isolates
}

\author{
Kenji YAMASHITA ${ }^{1)}$, Akira SHIMIZU ${ }^{1) *}$, Junichi KAWANO ${ }^{1)}$, Eiji UCHIDA $^{2)}$, Akihiro HARUNA ${ }^{3)}$ and \\ Shizunobu IGIMI ${ }^{4)}$ \\ ${ }^{1)}$ Department of Microbiology and Immunology, Faculty of Agriculture, Kobe University, 1-1 Rokkodai-cho, Nada-ku, Kobe, Hyogo 657- \\ $8501,{ }^{2}$ Department of Veterinary Internal Medicine II, School of Veterinary Medicine, Rakuno Gakuen University, 582-1 Bunkyodai \\ Midorimachi, Ebetsu, Hokkaido 069-8501, ${ }^{3)}$ Haruna Animal Hospital, 124-1 Ooda, Tsuyama, Okayama $708-0806$ and ${ }^{4)}$ Division of \\ Biomedical Food Research, National Institute of Health Sciences, 1-18-1 Kamiyoga, Setagaya-ku, Tokyo 158-8501, Japan
}

(Received 10 June 2004/Accepted 28 October 2004)

ABSTRACT. Staphylococci were isolated from the external auditory meatus in 14 (48.3\%) of 29 dogs affected with otitis externa (OE dogs) and $28(68.3 \%)$ of 41 dogs without OE (non-OE dogs). Twenty-two OE isolates were identified as belonging to 12 species, and 42 non$\mathrm{OE}$ isolates were identified as belonging to 13 species. The predominant species found in both OE and non-OE isolates were $S$. intermedius, and S. epidermidis. Thirty-eight (59.4\%) of 64 isolates were resistant to one or more of the 17 antimicrobial agents tested. Resistance to PCG and ABPC was most frequent. S. schleiferi subsp. coagulans, a recent etiologic agent of canine OE, was isolated from $\mathrm{OE}$ and non-OE dogs. All of the $5 \mathrm{~S}$. schleiferi subsp. coagulans isolates showed typical characteristics. No clear difference in the extracellular enzyme or toxin profiles, nor in the PFGE patterns, was demonstrated between the OE and non-OE isolates of $S$. schleiferi subsp. coagulans. A new PCR primer set specific for $16 \mathrm{~S}$ rDNA was designed to identify strains of $S$. schleiferi subsp. coagulans. The amplified fragment was detected in all of the 5 isolates as well as the type strain GA 211 (=JCM 7470) and a reference strain GA 11, but was not detected in any strains of the related species, S. aureus, S. intermedius and S. hyicus. The PCR may allow a simple, rapid and precise identification of $S$. schleiferi subsp. coagulans, in addition to the standard tube test for free coagulase.

KEY WORDS: canine external ear, identification, PCR, Staphylococcus schleiferi subsp. coagulans, Staphylococcus species.

J. Vet. Med. Sci. 67(3): 263-268, 2005

Otitis externa (OE) is common in dogs and is a disease of multifarious etiology. The yeast and bacterium most frequently isolated from OE dogs are Malassezia pachydermatis and Staphylococcus intermedius [2, 11, 20, 23], respectively. Staphylococci including $S$. intermedius are present in the nasal vestibulum, external auditory meatus, intestinal and urinogenital tracts, anal mucosa, and on the skin surface of dogs. Knowledge of the composition of the normal staphylococcal flora in the external auditory meatus is an important factor in determining the etiology and epidemiology of staphylococcal OE in dogs. However, the ecology of the staphylococci inhabiting the external auditory meatus of healthy dogs has not yet been studied sufficiently.

Determination of the susceptibility of Staphylococcus species to antimicrobial agents is of great importance in the selective use of chemotherapeutics, the evaluation of new antimicrobial agents, and in the development of drug resistance through continuous use of antimicrobial agents against field isolates. However, there is little information concerning the antimicrobial susceptibility patterns of Staphylococcus species isolated from $\mathrm{OE}$ and non-OE dogs in Japan [18].

Recently, coagulase-positive S. schleiferi subsp. coagu-

\footnotetext{
* Correspondence to: Shimizu, A., Department of Microbiology and Immunology, Faculty of Agriculture, Kobe University, 1-1 Rokkodai-cho, Nada-ku, Kobe, Hyogo 657-8501, Japan.
}

lans has also been isolated from the external auditory meatus of OE dogs [8]. Subsequently, the organism was cultured from dogs with pyoderma $[1,5,7]$ and from a finger-wound infection in a human patient [21]. Recognition of the clinical importance of $S$. schleiferi subsp. coagulans in veterinary and human medicine is growing. To our knowledge, there are no reports on the production of extracellular enzymes and toxins of putative virulence factors of the organism. Phenotypes of $S$. schleiferi subsp. coagulans are closely related to those of $S$. intermedius [8]. In routine laboratory practice, S. schleiferi subsp. coagulans can be distinguished from $S$. intermedius on the basis of its acetoin production and acid production from trehalose. However, more precise, rapid and simple identification systems are necessary to determine the etiology and epidemiology of $S$. schleiferi subsp. coagulans infections.

The present study was conducted to determine the species distribution and susceptibility to antimicrobial agents of staphylococci isolated from the external auditory meatus of OE dogs and non-OE dogs. We also examined the production of some extracellular active substances and the genotypes of $S$. schleiferi subsp. coagulans strains isolated in this study. In addition, we evaluated a PCR method designed to amplify species-specific sequences in the $16 \mathrm{~S}$ rDNA so that the strains of $S$. schleiferi subsp. coagulans could be identified. 


\section{MATERIALS AND METHODS}

Specimens: Samples were collected from 135 external auditory meatus of 29 OE dogs (53 ears) and 41 non-OE dogs (82 ears). The dogs tested visited one or the other of two hospitals in Hokkaido and Okayama prefectures between 2001 and 2002. The isolation of staphylococci was performed using swabs taken from the external auditory meatus of each dog.

Isolation of staphylococci: Swab specimens were directly inoculated onto heart infusion agar (Nissui Pharmaceutical Co., Ltd., Tokyo, Japan) supplemented with $7.5 \% \mathrm{NaCl}$, and were incubated aerobically for $48 \mathrm{hr}$ at $37^{\circ} \mathrm{C}$ with a further two or three days incubation at room temperature $\left(20^{\circ} \mathrm{C}\right.$ to $25^{\circ} \mathrm{C}$ ). Colony characteristics (morphology and pigment) were recorded for each different staphylococcal isolate, and one representative colony of each colony type per specimen was picked and transferred to heart infusion agar.

Identification of Staphylococcus species: Staphylococci were identified on the basis of colony characteristics, Gram stain and morphology, catalase reaction, colony pigmentation, and anaerobic acid production from glucose. Staphylococcus species were identified using the coagulase test and the ID32 Staph system (Bio Merieux, S.A., France).

Antimicrobial susceptibility tests: Antimicrobial susceptibility tests were performed with a commercially available paper disk diffusion method (Showa Yakuhin Kako Co., Ltd., Tokyo, Japan) using Sensitivity disk agar-N (Nissui). The antimicrobial agents tested were as follows: benzylpenicillin (PCG), ampicillin (ABPC), cefazolin (CEZ), cefmetazole (CMZ), imipenem (IPM), streptomycin (SM), kanamycin (KM), gentamicin (GM), erythromycin (EM), lincomycin (LCM), tetracycline (TC), doxycycline (DOXY), chloramphenicol (CP), norfloxacin (NFLX), ciprofloxacin (CPFX), ofloxacin (OFLX), and vancomycin (VCM). Detection of the mecA gene of antimicrobial resistant strains was carried out using the PCR method as described previously [10].

Detection of extracellular enzymes and toxins: Detection of extracellular enzymes of $S$. schleiferi subsp. coagulans was performed by the method of Hájek [6] and Devriese et al. [3, 4]. Staphylococcal enterotoxins (SEs; SEA, SEB, SEC, and SED), toxic shock syndrome toxin-1 (TSST-1), and staphylococcal exfoliative toxins (ETs; ET-A and ETB) were detected by the reversed-passive latex agglutination (RPLA) method using SET-RPLA, TSST-RPLA, and ETRPLA (Denka Seiken Co., Ltd., Tokyo, Japan), respectively.

Phage typing: Phage typing was performed as described previously [9] using 14 phages of the typing set for $S$. intermedius strains.

PFGE analysis: Preparation of chromosomal DNA and cleavage of genomic DNA with SmaI (New England BioLabs, Beverly, Mass.) were performed as described previously [17]. PFGE was performed with a $1 \%$ agarose slab gel (Seakem GTG, FMC Bioproducts, Rockland, Me.) using a CHEF-DR II system (Bio-Rad Laboratories Inc, Hercules,
Calif.) in $0.5 \times$ Tris-borate-EDTA maintained at $14^{\circ} \mathrm{C}$. The running parameters used were as follows: initial pulse time, $5 \mathrm{sec}$; final pulse time, $40 \mathrm{sec}$; voltage, $6 \mathrm{~V} / \mathrm{cm}$; running time, $22 \mathrm{hr}$. The PFGE patterns were interpreted based on the criteria of Tenover et al. [19].

$16 S$ rDNA specific PCR for identification of S. schleiferi subsp. coagulans: The bacteria were grown on a heart infusion agar (Nissui) plate at $37^{\circ} \mathrm{C}$ overnight. Bacterial DNA was extracted by a standard method as described previously [10]. A pair of primers was designed to amplify the $1369 \mathrm{bp}$ region of the $16 \mathrm{~S}$ rDNA of $S$. schleiferi subsp. coagulans (DDBJ accession number AB009945). Primer-1 (5'GAACGGACAAGGAGCTTGCTCCTTTGAA-3') and primer-2 (5'-GTTACAAACTCTCGTGGTGTGAA-3') correspond to the nucleotide residues 61 to 88 and 1407 to 1429, respectively. The PCR was performed in a $20-\mu l$ reaction volume. Each reaction mixture contained $1 \mu l(50$ to $150 n \mathrm{~g}$ ) of the sample DNA solution, $0.02 \mu \mathrm{M}$ of each primer, 0.5 units of Taq DNA polymerase (TaKaRa Taq, TaKaRa Shuzo Co., Ltd., Shiga, Japan), and $200 \mu \mathrm{M}$ of each $\mathrm{d}$ NTP (TaKaRa) in a PCR buffer $[10 \mathrm{mM}$ Tris-HCl $(\mathrm{pH}$ 8.3), $50 \mathrm{mM} \mathrm{KCl}, 1.5 \mathrm{mM} \mathrm{MgCl}_{2}$, TaKaRa]. The amplification reaction was carried out in a GeneAmp PCR System 9700 (Perkin-Elmer Applied Biosystems, U.S.A.) using the following program: $1 \mathrm{~min}$ at $94^{\circ} \mathrm{C}$, followed by 25 cycles of $1 \mathrm{~min}$ at $94^{\circ} \mathrm{C}, 1 \mathrm{~min}$ at $57^{\circ} \mathrm{C}$ and $2 \mathrm{~min}$ at $72^{\circ} \mathrm{C}$. The program was completed with an additional 7 -min extension step at $72^{\circ} \mathrm{C}$. After the amplification, $2 \mu l$ of the reaction mixture was analyzed by electrophoresis on a $1.5 \%$ agarose gel in Tris-acetete-EDTA buffer at $100 \mathrm{~V}$ for $20 \mathrm{~min}$ and stained with ethidium bromide. The identification of $S$. scheiferi subsp. coagulans was evaluated based on the size of amplication product.

\section{RESULTS}

Isolation of staphylococci: Staphylococci were isolated from the external auditory meatus in $14(48.3 \%)$ of $29 \mathrm{OE}$ dogs and $28(68.3 \%)$ of 41 non-OE dogs (Table 1). Twentytwo $\mathrm{OE}$ isolates were identified as belonging to 12 species, and 42 non-OE isolates were identified as belonging to 13 species. S. intermedius and S. epidermidis were the predominant species isolated from $\mathrm{OE}$ and non-OE dogs.

S. schleiferi subsp. coagulans strains were identified by means of $16 \mathrm{~S}-23 \mathrm{~S}$ rDNA intergenic spacer PCR analysis [14], of which the length polymorphisms of $S$. schleiferi subsp. coagulans were the same as that of $S$. schleiferi subsp. schleiferi (Fig. 1), and also by means of metabolic characteristics such as the production of free coagulase with rabbit plasma, acetoin and $\beta$-hemolysin, and the lack of acid production from trehalose or maltose.

Antimicrobial susceptibility tests: The results of antimicrobial susceptibility tests for 64 staphylococcal isolates including 15 species are presented in Table 2. Thirty-eight $(59.4 \%)$ isolates were resistant to one or more of the 17 antimicrobial agents tested. Resistance to PCG (56.3\% of strains) and ABPC (54.7\%) was the most frequent, followed 
Table 1. Species distribution of staphylococci isolated from the external auditory meatus of $\mathrm{OE}^{\mathrm{a})}$ and non-OE dogs

\begin{tabular}{|c|c|c|}
\hline \multirow[b]{2}{*}{ Species } & \multicolumn{2}{|c|}{ Frequency of isolation } \\
\hline & $\begin{array}{c}\text { OE dogs } \\
14 / 29^{b)}(48.3 \%)\end{array}$ & $\begin{array}{l}\text { Non-OE dogs } \\
28 / 41(68.3 \%)\end{array}$ \\
\hline S. intermedius & $4^{\text {c) }}(28.6 \%)$ & $11(39.3 \%)$ \\
\hline S. aureus & $1(7.1 \%)$ & $1(3.6 \%)$ \\
\hline S. schleiferi subsp. coagulans & $s \quad 2(14.3 \%)$ & 1 \\
\hline S. capitis & 1 & $2(7.1 \%)$ \\
\hline S. caprae & 1 & 2 \\
\hline S. chromogenes & 1 & 1 \\
\hline S. cohnii subsp. cohnii & 1 & 0 \\
\hline S. epidermidis & $5(35.7 \%)$ & $7(25.0 \%)$ \\
\hline S. haemolyticus & 1 & 0 \\
\hline S. hominis & 0 & 1 \\
\hline S. lentus & 0 & 1 \\
\hline S. saprophyticus & 2 & $5(17.9 \%)$ \\
\hline S. sciuri & 1 & 1 \\
\hline S. warneri & 1 & $3(10.7 \%)$ \\
\hline S. xylous & 0 & 3 \\
\hline Unidentifiable & $4(28.6 \%)$ & $8(28.6 \%)$ \\
\hline
\end{tabular}

a) OE: otitis externa.

b) No. of positive dogs/No. of dogs examined.

c) No. of individuals from which Staphylococcus species were isolated.

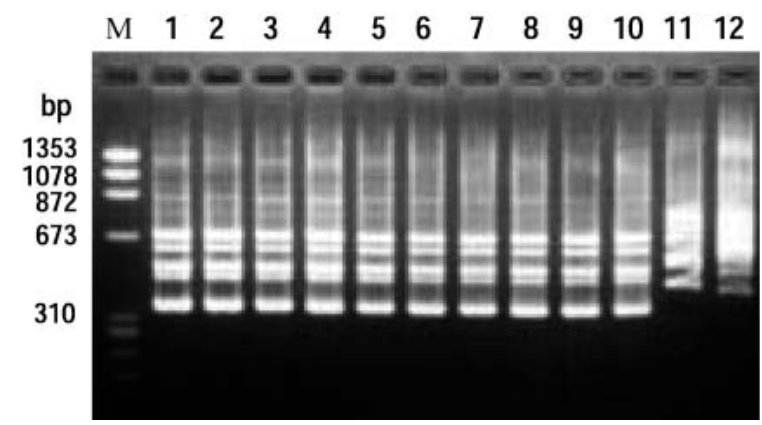

Fig. 1. 16S-23S rDNA intergenic spacer region patterns of $S$. schleiferi subsp. coagulans. Lanes: M, size markers; $1-5$, isolates in this study; $6-8$, reference strains (GA 11, GA 64, and GA 288) [8]; 9, the type strain GA 211 (=JCM 7470) [8]; 10, S. schleiferi subsp. schleiferi (the type strain ATCC 43808); 11, S. aureus (strain FDA 209P); 12, S. intermedius (the type strain ATCC 29663).

by KM (14.1\%), EM (14.1\%), NFLX (9.4\%), LCM (7.8\%), SM (6.3\%), CPFX (3.1\%), OFLX (3.1\%), TC (3.1\%), and GM $(1.6 \%)$. Three $(7.9 \%)$ and $35(92.1 \%)$ of the resistant isolates were single and multiple resistant types, respectively. Furthermore, 38 resistant isolates were examined for the presence of the mecA gene. Two isolates of $S$. caprae and one isolate of $S$. xylosus carried the mecA gene.

Characteristics of S. schleiferi subsp. coagulans: Five isolates of $S$. schleiferi subsp. coagulans from OE dogs (Nos. 1 and 2) and non-OE dog (No. 3) unexceptionally produced coagulase, $\beta$-hemolysin, DNase, lipase, and protease, but failed to produce gelatinase, staphylokinase, hyaluronidase, protein A, SEs, TSST-1, and ETs (Table 3).
All of the 5 isolates were sensitive to phages of the phage set for $S$. intermedius. Three isolates showed the phage pattern $06 / 40 / 58 / 93$, and the remaining 2 isolates showed 06/40/58 and 06/40/58/93/E74. The PFGE patterns of the 5 isolates are shown in Fig. 2. Identical PFGE patterns were shown in isolates from the left and right ears of individual dogs (Nos. 2 and 3) (Table 3). The PFGE pattern of the OE isolate in Hokkaido (No.1) was similar to that of OE isolates in Okayama (No.2), which is located geographically at a great distance from Hokkaido. In addition, $\mathrm{OE}$ and non-OE isolates showed similar patterns, suggesting that they were genetically closely related.

16S rDNA specific PCR for identification of S. schleiferi subsp. coagulans: The 16S rDNA of $S$. schleiferi subsp. coagulans, of which the PCR target fragment was made up of $1369 \mathrm{bp}$ corresponding to the sequences of the gene, was detected in all of the 5 isolates of $S$. schleiferi subsp. coagulans as well as in the type strain GA 211 (=JCM 7470) and the reference strain GA 11 (Fig. 3). For the strains of $S$. aureus $(\mathrm{n}=5)$, S. intermedius $(\mathrm{n}=5)$, and S. hyicus $(\mathrm{n}=2)$ used to confirm the specificity of the PCR, the specific amplification product was not observed.

\section{DISCUSSION}

One purpose of this study was to determine the species distribution and susceptibility to antimicrobial agents of staphylococci from the external auditory meatus of $\mathrm{OE}$ and non-OE dogs.

Novobiocin-sensitive species were the predominant inhabitants in the external auditory meatus of the two groups of dogs. The most frequently isolated species were $S$. intermedius and S. epidermidis. This result agrees in gross with the study performed by Uchida et al. [20], who found that the commonly isolated novobiocin-sensitive species were $S$. intermedius, S. chromogenes, and S. haemolyticus in $\mathrm{OE}$ dogs, and $S$. chromogenes and $S$. epidermidis in non-OE dogs.

Resistance to PCG or ABPC is common in staphylococci of dog origin $[12,13]$. In the present study, about $60 \%$ of the 64 staphylococcal isolates were resistant to one or more of the antimicrobial agents tested. Resistance to PCG and $\mathrm{ABPC}$ was found in $56.3 \%$ and $54.7 \%$ of the strains, respectively. Interestingly, resistance to these antimicrobial agents was detected in 11 Staphylococcus species. The quinolones are approved for use in small animal medicine in Japan. The frequencies of resistance to NFLX, OPLX and CPFX were low, ranging from $3.1 \%$ to $9.4 \%$, showing that resistance to quinolones among staphylococci is still rare in dogs. Among 3 coagulase-positive staphylococci, S. aureus and $S$. schleiferi subsp. coagulans isolates were susceptible to all of the 17 tested antimicrobials, while about $83 \%$ of $S$. intermedius isolates were resistant, and all of the $S$. intermedius isolates were resistant to PCG and ABPC. The high frequency of resistance to these antimicrobial agents has already been reported in $S$. intermedius of dog origin in the United States [13,16] and the UK [15]. Quinolone-resistant 
Table 2. Antimicrobial resistance patterns of staphylococcal isolates from the external auditory meatus of OE and non-OE dogs

\begin{tabular}{|c|c|c|}
\hline Species & $\begin{array}{l}\text { No. of antimicrobial } \\
\text { resistant isolates/ } \\
\text { No. of isolates tested }\end{array}$ & Antimicrobial resistance pattern (Origin and No. of isolates) \\
\hline S. intermedius & $14 / 17(82.4 \%)$ & $\begin{array}{l}\mathrm{PCG} / \mathrm{ABPC}(\mathrm{OE}, 2 ; \text { non-OE, 7), PCG/ABPC/KM(non-OE, 1), } \\
\mathrm{PCG} / \mathrm{ABPC} / \mathrm{EM} / \mathrm{KM} / \mathrm{SM}(\text { non-OE, 1) } \\
\mathrm{PCG} / \mathrm{ABPC} / \mathrm{EM} / \mathrm{KM} / \mathrm{SM} / \mathrm{LCM}(\mathrm{OE}, 1 \text {; non-OE, } 1) \\
\mathrm{PCG} / \mathrm{ABPC} / \mathrm{EM} / \mathrm{KM} / \mathrm{SM} / \mathrm{LCM} / \mathrm{NFLX} / \mathrm{CPLX} / \mathrm{OFLX}(\text { non-OE, } 1) \text {, }\end{array}$ \\
\hline S. aureus & $0 / 2$ & \\
\hline S. schleiferi subsp. coagulan & $0 / 5$ & \\
\hline S. capitis & $2 / 3(66.7 \%)$ & PCG(non-OE, 1), PCG/ABPC(OE, 1) \\
\hline S. caprae & $3 / 3(100 \%)$ & $\begin{array}{l}\text { PCG/ABPC(non-OE, 1), PCG/ABPC/KM/NFLX(non-OE, } 1)^{\mathrm{a})} \\
\text { PCG/ABPC/NFLX/CPFX/OFLX(OE, 1) }\end{array}$ \\
\hline S. chromogenes & $0 / 2$ & \\
\hline S. cohnii subsp. cohnii & $1 / 1(100 \%)$ & PCG/ABPC(OE, 1) \\
\hline S. epidermidis & $6 / 12(50.0 \%)$ & $\begin{array}{l}\text { PCG/ABPC(OE, 1; non-OE, 3), PCG/ABPC/KM/NFLX(non-OE, 1), } \\
\text { EM(non-OE, 1) }\end{array}$ \\
\hline S. haemolyticus & $1 / 1(100 \%)$ & PCG/ABPC/TC/KM/GM/NFLX(OE, 1) \\
\hline S. hominis & $1 / 1(100 \%)$ & PCG/ABPC/EM(non-OE, 1) \\
\hline S. lentus & $0 / 1$ & \\
\hline S. saprophyticus & $3 / 7(42.9 \%)$ & PCG/ABPC(non-OE, 3) \\
\hline S. sciuri & $2 / 2(100 \%)$ & PCG/ABPC(OE, 1), PCG/ABPC/EM/TC/KM(non-OE, 1) \\
\hline S. warneri & $2 / 4(50.0 \%)$ & $\mathrm{PCG} / \mathrm{ABPC} / \mathrm{KM}(\mathrm{OE}, 1), \mathrm{NFLX}($ non-OE, 1) \\
\hline S. xylsous & $3 / 3(100 \%)$ & PCG/ABPC(non-OE, 1), PCG/ABPC/EM/LCM(non-OE, 2) $\left.)^{a}\right)$ \\
\hline Total & $38 / 64(59.4 \%)$ & \\
\hline
\end{tabular}

Table 3. Characteristics of S. schleiferi subsp. coagulans isolates

\begin{tabular}{|c|c|c|c|c|c|}
\hline \multirow{4}{*}{ Characteristic } & \multicolumn{3}{|c|}{$\mathrm{OE}$} & \multirow{3}{*}{\multicolumn{2}{|c|}{$\begin{array}{l}\text { Non-OE } \\
\text { Hokkaido } \\
\text { Dog No.3 }\end{array}$}} \\
\hline & \multirow{3}{*}{$\begin{array}{l}\text { Hokkaido } \\
\text { Dog No.1 } \\
\text { Right ear }\end{array}$} & \multirow{2}{*}{\multicolumn{2}{|c|}{$\begin{array}{l}\text { Okayama } \\
\text { Dog No.2 }\end{array}$}} & & \\
\hline & & & & & \\
\hline & & Left ear & Right ear & Leftear & Rightear \\
\hline Coagulase for rabbit plasma & + & + & + & + & + \\
\hline Enterotoxins (A, B, C, D) & - & - & - & - & - \\
\hline$\alpha$-hemolysin & - & - & - & - & - \\
\hline$\beta$-hemolysin & + & + & + & + & + \\
\hline TSST-1 toxin & - & - & - & - & - \\
\hline Exfoliative toxins (ET-A, ET-B) & - & - & - & - & - \\
\hline DNase & + & + & + & + & + \\
\hline Gelatinase & - & - & - & - & - \\
\hline Lipase & $+\mathrm{w}^{\mathrm{a})}$ & $+\mathrm{w}$ & $+\mathrm{w}$ & $+\mathrm{w}$ & $+\mathrm{w}$ \\
\hline Protease & + & + & + & + & + \\
\hline Staphylokinase & - & - & - & - & - \\
\hline Hyaluronidase & - & - & - & - & - \\
\hline Protein A & - & - & - & - & - \\
\hline \multirow{2}{*}{ Phage pattern } & $06 / 40 /$ & $06 / 40 / 58$ & $06 / 40 / 58 /$ & $06 / 40 /$ & $06 / 40 /$ \\
\hline & $58 / 93$ & & 93/E74 & $58 / 93$ & $58 / 93$ \\
\hline
\end{tabular}

a) Weak reaction.

S. intermedius was not isolated from healthy and diseased dogs from 1982 to 1999 [18], and only one of the 17 isolates in this study was quinolone-resistant. With respect to methicillin resistance, 2 isolates of $S$. caprae and one isolate of $S$. xylosus were found to be resistant to methicillin. This is the first evidence of the existence of methicillin-resistant $S$. caprae in dogs.

Another purpose of this study was to characterize $S$. schleiferi subsp. coagulans isolates by using biological properties and PFGE typing and to develop a PCR method for the identification of this organism based on the $16 \mathrm{~S}$ rDNA sequence.

The clinical significance of $S$. schleiferi subsp. coagulans has been fully ascertained. Igimi et al. [8] suggested a pathogenic role for the organism in canine OE. Recently, the organism has also been isolated from dogs affected with pyoderma $[1,5,7]$ and from a finger wound infection in a human [21]. No previous studies on the production of extra- 


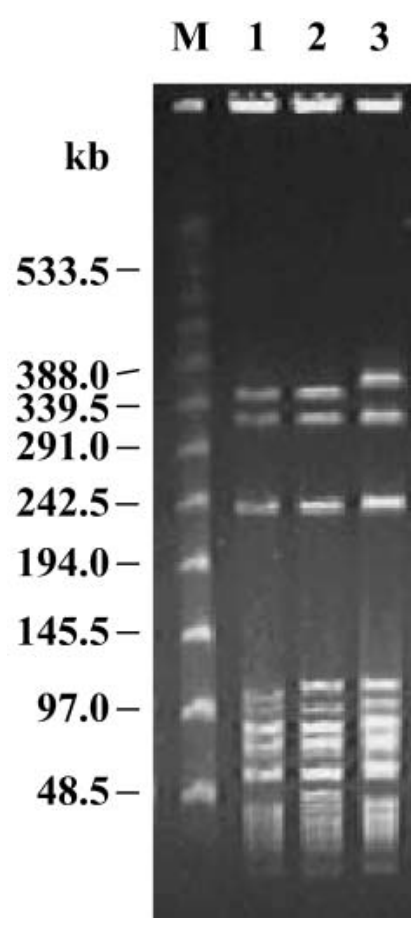

Fig. 2. PFGE of Sma I-digested genomic fragments of S. schleiferi subsp. coagulans isolated from $\mathrm{OE}$ and non-OE dogs. Lanes: M, size markers; 1, one isolate from OE dog (No. 1) in Hokkaido; 2, two isolates from left and right ears of OE dog (No. 2) in Okayama; 3, two isolates from left and right ears of non-OE dog (No.3) in Hokkaido. See Table 3 for the origin and characteristics of isolates. cellular enzymes and toxins of $S$. schleiferi subsp. coagulans isolated from dogs and a human have been conducted. In the present study, 5 isolates of S. schleiferi subsp. coagulans from $\mathrm{OE}$ and non-OE dogs were compared for their ability to produce a range of virulence-associated factors, which are thought to contribute to the pathogenicity of the organism. However, no clear differences in the extracellular enzyme and toxin profiles between the two groups of isolates were demonstrated. PFGE analysis also showed that both of the $\mathrm{OE}$ and non-OE isolates are very closely related. These results suggest that similar or identical strains of $S$. schleiferi subsp. coagulans found in OE dogs are distributed in non-OE dogs, though the number of strains examined in this study was too small to draw a definite conclusion. A detailed comparison of the characteristics between $\mathrm{OE}$ and non-OE isolates should be studied in future.

S. intermedius is a representative pathogenic bacterium that is frequently isolated from dogs with $\mathrm{OE}$ and pyoderma. Strains of $S$. schleiferi subsp. coagulans are phenotypically similar to strains of $S$. intermedius. Simple identification systems for correctly identifying strains of S. schleiferi subsp. coagulans are not currently available. The PCR primers designed in this study gave a rapid and simple identification of the organism. Though the PCR in this study cannot distinguish $S$. scheiferi subsp. coagulans from $S$. schleiferi subsp. schleiferi, as reported by Frank et al. [5], it is easy to differentiate these two subspecies on the basis of their tube coagulase test [8] and urease production [21]. Previously, we [22] designed a primer set for PCR specific for $16 \mathrm{~S}$ rDNA in order to identify the strains of canine pathogenic $S$. intermedius. These two primer sets for PCR

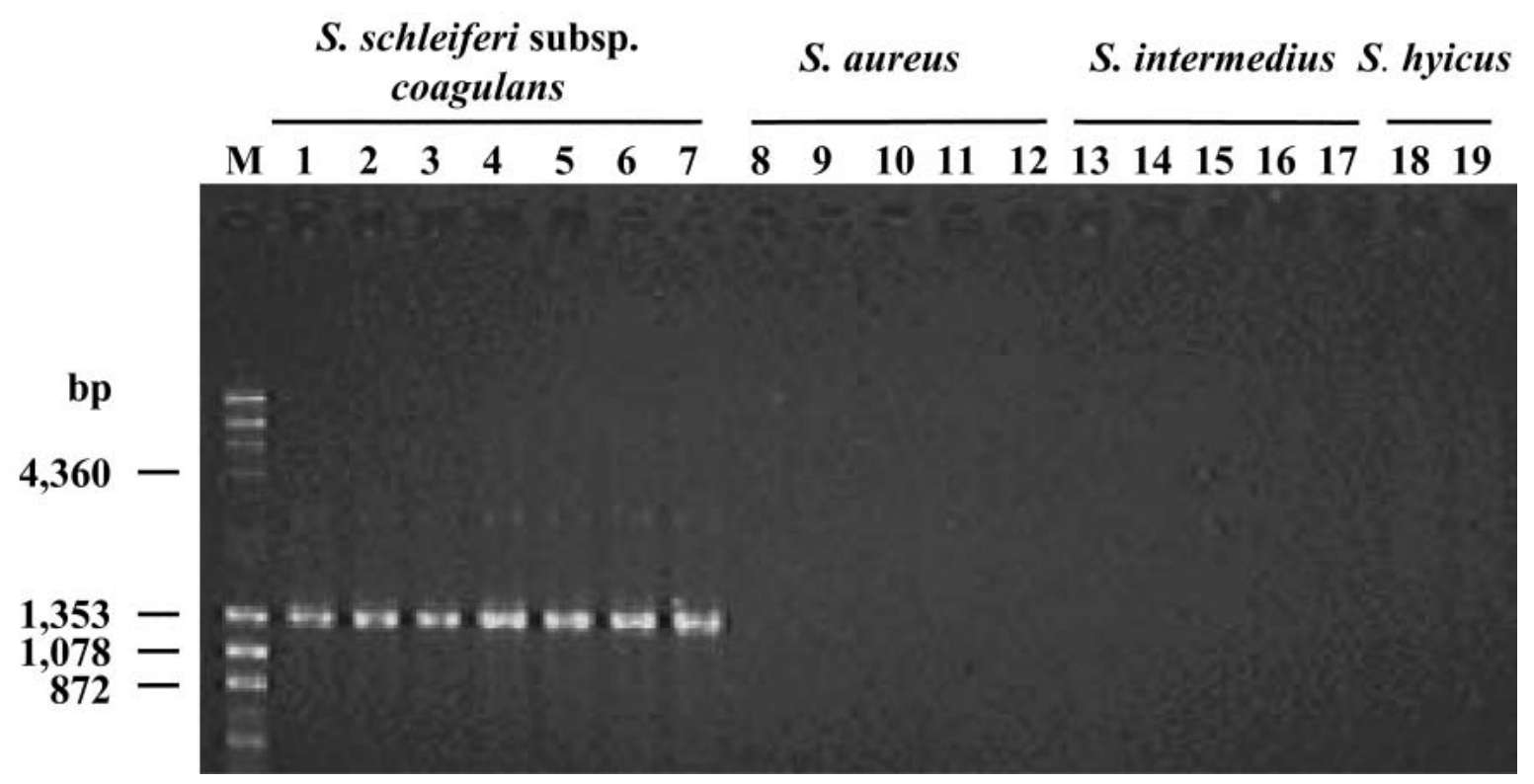

Fig. 3. Agarose gel electrophoresis of the PCR products from strains of S. schleiferi subsp. coagulans, S. aureus, S. intermedius, and S. hyicus. Lanes: M, size markers; 1, the type strain GA 211 (=JCM 7470) [8]; 2, a reference strain GA 11 [8]; 3-7, dog isolates in this study; 8, strain FDA 209P; 9, NCTC 10442; 10, chicken strain; 11-12, dog strains; 13, type strain ATCC 29663; 14-17, dog strains; 18, type strain NCTC 10350; 19, chicken strain. 
specific for the 16S rDNA of $S$. schleiferi subsp. coagulans or $S$. intermedius are useful for determining the etiology and epidemiology of the canine staphylococcal infections that spawn these coagulase-positive species.

\section{REFERENCES}

1. Bes, M., Guérin-Faublée, V., Freney, J. and Etienne, J. 2002. Isolation of Staphylococcus schleiferi subspecies coagulans from two cases of canine pyoderma. Vet. Rec. 150: 487-488.

2. Cole, L.K., Kwochka, K.W., Kowalski, J.J. and Hillier, A. 1998. Microbial flora and antimicrobial susceptibility patterns of isolated pathogens from the horizontal ear canal and middle ear in dogs with otitis media. J. Am. Vet. Med. Assoc. 212: 534-538.

3. Devriese, L.A. 1984. A simplified system for biotyping Staphylococcus aureus strains isolated from different animal species. J. Appl. Bacteriol. 56: 215-220.

4. Devriese, L.A. and Oeding, P. 1975. Coagulase and heat-resistant nuclease producing Staphylococcus epidermidis strains from animals. J. Appl. Bacteriol. 39: 197-207.

5. Frank, L.A., Kania, S.A., Hnilica, K.A., Wilkes, R.P. and Bemis, D.A. 2003. Isolation of Staphylococcus schleiferi from dogs with pyoderma. J. Am. Vet. Med. Assoc. 222: 451-454.

6. Hájek, V. 1976. Staphylococcus intermedius, a new species isolated from animals. Int. J. Syst. Bacteriol. 26: 401-408.

7. Holm, B.R., Petersson, U., Mörner, A., Bergström, K., Franklin, A. and Creko, C. 2002. Antimicrobial resistance in staphylococci from canine pyoderma: a prospective study of firsttime and recurrent cases in Sweden. Vet. Rec. 151: 600-605.

8. Igimi, S., Takahashi, E. and Mitsuoka, T. 1990. Staphylococcus schleiferi subsp. coagulans subsp. nov., isolated from the external auditory meatus of dogs with external ear otitis. Int. J. Syst. Bacteriol. 40: 409-411.

9. Kawano, J., Shimizu, A., Kimura, S. and Blouse, L. 1982. Experimental bacteriophage set for typing Staphylococcus intermedius. Zbl. Bakt. Hyg., I. Abt. Orig. A 253: 321-330.

10. Kawano, J., Shimizu, A., Saitoh, Y., Yagi, M., Saito, T. and Okamoto, R. 1996. Isolation of methicillin-resistant coagulase-negative staphylococci from chickens. J. Clin. Microbiol. 34: 2072-2077.

11. Kiss, G., Radványi, Sz. and Szigeti, G. 1997. New combination for the therapy of canine otitis externa. I. Microbiology of otitis externa. J. Small Anim. Pract. 38: 51-56.

12. Kruse, H., Hofshagen, M., Thoresen, S.I., Bredal, W.P., Vollset, I. and Søli, N.E. 1996. The antimicrobial susceptibility of Staphylococcus species isolated from canine dermatitis. Vet. Res. Commun. 20: 205-214.

13. Medleau, L., Long, R.E., Brown, J. and Miller, W.H. 1986. Frequency and antimicrobial susceptibility of Staphylococcus species isolated from canine pyoderma. Am. J. Vet. Res. 47: 229-231.

14. Mendoza, M., Meugnier, H., Bes, M., Etienne, J. and Freney, J. 1998. Identification of Staphylococcus species by $16 \mathrm{~S}-23 \mathrm{~S}$ rDNA intergenic spacer PCR analysis. Int. J. Syst. Bacteriol. 48: 1049-1055.

15. Noble, W.C. and Kent, L.E. 1992. Antibiotic resistance in Staphylococcus intermedius isolated from cases of pyoderma in the dog. Vet. Dermatol. 3: 71-74.

16. Phillips, W.E., Jr. and Williams, B.J. 1984. Antimicrobial susceptibility patterns of canine Staphylococcus intermedius isolates from veterinary clinical specimens. Am. J. Vet. Res. 45: 2376-2379.

17. Shimizu, A., Berkhoff, H.A., Kloos, W.E., George, C.G. and Ballard, D.N. 1996. Genomic DNA fingerprinting, using pulsed-field gel electrophoresis, of Staphylococcus intermedius isolated from dogs. Am. J. Vet. Res. 57: 1458-1462.

18. Shimizu, A., Wakita, Y., Nagase, S., Okabe, M., Koji, T., Hayashi, T., Nagase, N., Sasaki, A., Kawano, J., Yamashita, K. and Takagi, M. 2001. Antimicrobial susceptibility of Staphylococcus intermedius isolated from healthy and diseased dogs. $J$. Vet. Med. Sci. 63: 357-360.

19. Tenover, F.C., Arbeit, R.D., Goering, R.V., Mickelsen, P.A., Murray, B.E., Persing, D.H. and Swaminathan, B. 1995. Guest commentary. Interpreting chromosomal DNA restriction patterns produced by pulsed-field gel electrophoresis: criteria for bacterial strain typing. J. Clin. Microbiol. 33: 2233-2239.

20. Uchida, Y., Nakada, T. and Kitazawa, K. 1990. Clinico-microbiological study of the normal and otitic external ear canals in dogs and cats. Jpn. J. Vet. Sci. 52: 415-417.

21. Vandenesch, F., Lebeau, C., Bes, M., Lina, G., Lina, B., Greenland, T., Benito, Y., Brun, Y., Fleurette, J. and Etienne, J. 1994. Clotting activity in Staphylococcus schleiferi subspecies from human patients. J. Clin. Microbiol. 32: 388-392.

22. Wakita, Y., Kawano, J., Shimizu, A., Hájek, V., Tomisaka, E., Yasuda, R. and Matsuo, E. 2002. Development of a PCR test for the identification of Staphylococcus intermedius based on the 16S rDNA sequence. J. Vet. Med. Sci. 64: 603-605.

23. Yoshida, N., Naito, F. and Fukata, T. 2002. Studies of certain factors affecting the microenvironment and microflora of the external ear of the dog in health and disease. J. Vet. Med. Sci. 64: $1145-1147$. 